\title{
Postrenal acute kidney injury and abdominal compartment syndrome associated with bladder pressure: type III rectus sheath hematoma
}

Emre Bozdağ, Ebubekir Gündeş, Ulaş Aday, Hüseyin Çiyiltepe, Durmuş Ali Çetin, Selçuk Gülmez, Aziz Serkan Senger

Gastroenterological Surgery Department, Kartal Koşuyolu High Speciality and Training Hospital, Istanbul, Turkey

Submitted: 20 January 2017

Accepted: 16 February 2017

Arch Med Sci Atheroscler Dis 2017; 2: e1-e2

DOI: https://doi.org/10.5114/amsad.2017.66479

Copyright $\odot 2017$ Termedia \& Banach

Clinically speaking, spontaneous rectus sheath hematoma (RSH), a rare cause of acute abdominal pain, is usually a self-limiting condition [1]. However, failure to diagnose it can result in death. Patients taking anticoagulants should be especially aware of its symptoms. It is most commonly observed on the right side below the umbilicus and almost always presents as unilateral [2]. The RSH is two or three times more common in females than in males. Although there are many possible risk factors, the current popularity of anticoagulant treatment has resulted in an increase in the number of spontaneous cases of RSH being reported [3, 4].

In the current case, a 58-year-old female patient presented to the cardiovascular surgery clinic with complaints of dyspnea and fatigue. The patient was admitted with heart failure and aortic stenosis. Her medical history included mitral valve operations 12 and 19 years ago, and she was taking warfarin at a dose of $5 \mathrm{mg} /$ day. Due to the sudden onset of swelling and fullness in the right lower quadrant during this hospital admission, we were consulted regarding her condition. There was no trauma in the patient's medical history, and no use of anticoagulants. During the physical examination, her general condition was observed to be moderate, normotensive, and normocardic. However, there was tenderness to palpation observed on the right lower abdominal quadrant, as well as a detectable mass with unclear borders. Bowel sounds were normoactive. Laboratory values were as follows: hemoglobin: $8.3 \mathrm{~g} / \mathrm{dl}$; hematocrit (hct): 27\%; international normalized ratio (INR) $6.14 \mathrm{~min}$; activated partial thromboplastin time (APTT): 45.6 s; leukocytes: $35400 \mu$; platelets: $306000 \mu \mathrm{l}$; urea: $40 \mathrm{~g} / \mathrm{dl}$; creatinine: $0.8 \mathrm{mg} / \mathrm{dl}$. Abdominal tomography with intravenous contrast was performed on the patient. The tomography revealed a type I RSH in the right lower quadrant (Figure 1). With these findings the patient was followed up.

It was observed that the fullness in the right lower quadrant had advanced to the bilateral lower quadrant and the upper limit of the umbilicus. Furthermore, the hct level had decreased to $20 \%$ and the creatinine level had increased to $1.8 \mathrm{mg} / \mathrm{dl}$. During this time, 4 units of red blood cells were transfused to the patient. In the same period hourly urine output decreased, and $6 \mathrm{~h}$ later the patient was unable to urinate at all. However, during this period there was no deterioration of vital signs (pulse rate was $90-100 / \mathrm{min}$ and arterial blood pressure was around

\author{
Corresponding author: \\ Ebubekir Gündeş \\ Gastroenterological Surgery \\ Department \\ Kartal Koşuyolu \\ High Speciality and \\ Training Hospital \\ Denizer cad. No: 22 \\ 34000 Istanbul, Turkey \\ Phone: +90 5058606740 \\ E-mail: ebubekir82@hotmail. \\ com
}




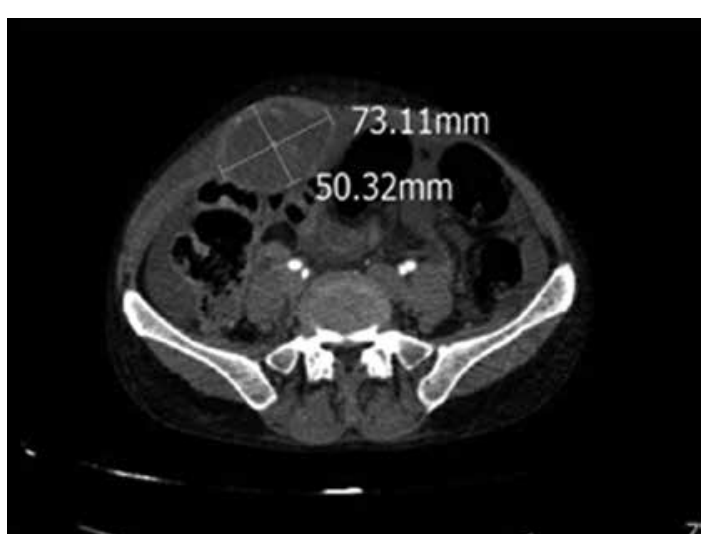

Figure 1. Image of first computed tomography (type I RSH)

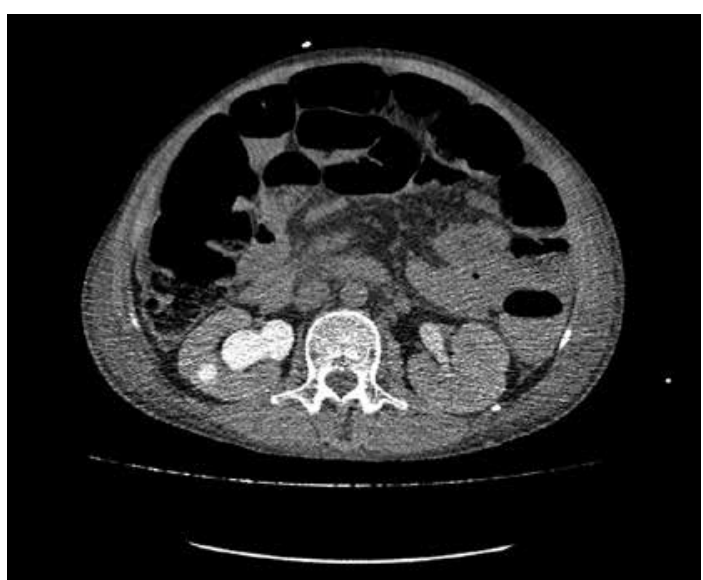

Figure 3. Second computed tomography image of bilateral renal pelvic grade $2-3$ hydronephrosis

135/70). Additionally, intra-abdominal pressure measurements were taken in order to differentiate between abdominal distention and a possible case of abdominal compartment syndrome. Sterile isotonic was administered to the emptied bladder with a branule inserted on a Foley catheter, but failed due to high pressure. The process was repeated several times, but failed in each instance. In order to check for a hematoma, an unenhanced computed tomography (CT) scan was performed on the patient with low hct, severe progression on physical examination and stable vital signs. During the tomography, an enlarged hematoma (type III RSH) was detected that filled the bilateral lower quadrants, compressing the bladder and causing grade $2-3$ hydronephrosis in both kidneys (Figures 2-3).

The patient was operated on under urgent conditions, considering the diagnoses of abdominal compartment syndrome and postrenal acute kidney injury. Approximately $3000 \mathrm{ml}$ of hematoma-coagulum was evacuated from under the rectus muscle without opening the parietal peritoneum. There was no active bleeding in vessels. In the postoperative follow-ups after decompression,

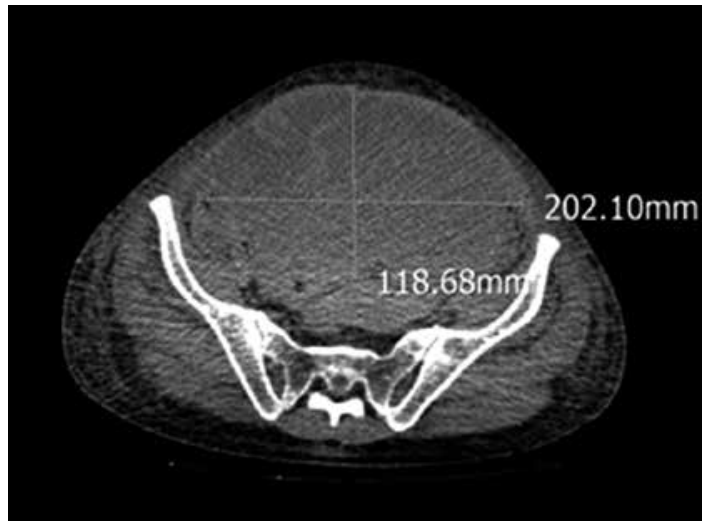

Figure 2. Image of second computed tomography (type III RSH)

the patient was seen to have sufficient urinary output. Her urea and creatinine values were also normal. On the $11^{\text {th }}$ postoperative day, the patient was discharged without any complications.

In conclusion, RSH is usually a self-limiting condition that can lead to potentially serious complications, including obstructive uropathy [1] and abdominal compartment syndrome [2]. As RSH mostly limits itself, treatment is conservative. However, surgical treatment is indicated for large hematomas creating hemodynamic deterioration and complex hematomas (peritoneal rupture, infection). In addition to these indications, surgery may also be recommended for the treatment of gross hematomas that may cause obstructive uropathy and abdominal compartment syndrome $[3,4]$.

\section{Conflict of interest}

The authors declare no conflict of interest.

\section{References}

1. Toyonaga J, Tsuruya K, Masutani K, et al. Hemorrhagic shock and obstructive uropathy due to a large rectus sheath hematoma in a patient on anticoagulant therapy. Intern Med 2009; 48: 2119-22.

2. Jafferbhoy SF, Rustum Q, Shiwani MH. Abdominal compartment syndrome - a fatal complication from a rectus sheath haematoma. BMJ Case Reports 2012; 2012. pii: bcr1220115332.

3. Klingler PJ, Wetscher G, Glaser K, Tschmelitsch J, Schmid T, Hinder RA. The use of ultrasound to differentiate rectus sheath hematoma from other acute abdominal disorders. Surg Endosc 1999; 13: 1129-34.

4. Salemis NS, Gourgiotis S, Karalis G. Diagnostic evaluation and management of patients with rectus sheath hematoma. A retrospective study. Int J Surg 2010; 8: 290-3. 